\title{
COMPUTER ART AND TECHNOCULTURES: EVALUATING THE V\&A'S COLLECTIONS IN THE DIGITAL AGE
}

\author{
Douglas Dodds \\ Word \& Image Department \\ Victoria and Albert Museum \\ South Kensington \\ London \\ UK \\ d.dodds@,vam.ac.uk \\ www.vam.ac.uk
}

\begin{abstract}
The presentation provides an overview of the Victoria and Albert Museum's collections of computer-generated artworks, focussing on recent acquisitions such as the Patric Prince Collection and the archives of the Computer Arts Society. The paper then goes on to describe an Arts and Humanities Research Council (AHRC) funded project entitled "Computer Art and Technocultures", a collaboration between the V\&A and Birkbeck College that is examining the Museum's collections and placing them in a broader art-historical, social and technological context. Outcomes will include a database of artworks, a conference and/or study days, plus one or more publications and a display in the $V \& A$.
\end{abstract}

\section{INTRODUCTION}

The V\&A's Word and Image Department holds the Museum's main collections of prints, drawings, paintings, photographs, books, archives and manuscripts. The Department has more than 2 million objects in total, including some 750,000 prints, drawings, paintings and photographs. Anything that is not on loan or display can be consulted in the Museum's Prints and Drawings Study Room, the National Art Library or the Archive of Art and Design.

\section{THE V\&A'S COMPUTER ART COLLECTIONS}

In the early days of the South Kensington Museum, the institution covered a much wider range of disciplines than it does today, and the relationship between art and science was very much a feature of the Museum's collections. Until recently, however, the V\&A held relatively few works that illustrate the early years of computer-generated art and design. During the 1970s and 80s, the Museum's Prints, Drawings and Paintings Department (as it was then known) did collect some works by notable computer artists, but these were few and far between. Computer art was somewhat unfashionable at the time, at least among many art historians and commentators. Curators were also understandably concerned that the original material might be difficult to display, and they were equally concerned about the durability of the artworks themselves.

Of course, many major artists now make extensive use of computer technology, and this is no longer a source of surprise or concern to curators or critics. Nowadays, the Museum's prints, drawings and photographs collections attempt to reflect this transformation in practice. Recent acquisitions include Loyal and dependable (2002), a 
series of Iris prints by Willie Cole that includes a digitally-manipulated image of a domestic iron; I dreamt I was driving my car (motorway corner) (2002) by Julian Opie; Family portrait (2002) by Marilène Oliver, who gave a presentation at last year's conference; and Award (2004), a set of digital inkjet prints by Peter Kennard and Cat Picton Phillips.

Nevertheless, the Museum has acquired relatively few born-digital works for its permanent collection. Instead, we have preferred to commission digital artists and designers to produce works for various temporary displays, many of them organised by the V\&A's Contemporary team. Examples include Digital $>$ Responses (2002-3), in which artists created works in response to objects and spaces in the V\&A; Volume (2006-7), a luminous interactive installation in the Museum's John Madejski Garden; and a number of special events on Friday evenings. (My colleague Louise Shannon is currently involved in planning a Digital Responses display in 2009, and will be speaking about the Museum's digital programming later in the conference.)

In the past few years, though, we have actively sought to develop our computer art collections. Some early practitioners rapidly moved on to related fields such as animation or computer graphics, an area which is very much of relevance to the V\&A. Given the Museum's status as the national museum of design, these artists, designers and programmers thus remain of interest and are now becoming much more appreciated than they were at the time. Indeed, the acquisition of the Patric Prince Collection and, more recently, the archives of the Computer Arts Society have ensured that the V\&A has now established the basis for an emerging national collection of computer art from the 1960s onwards. Pioneers represented in the Museum's holdings include Paul Brown, Harold Cohen, Charles Csuri, David Em, Herbert Franke, Jean-Pierre Hébert, Ken Knowlton, Tony Longson, Manfred Mohr, Vera Molnar, Kamran Moojedi, Frieder Nake, Georg Nees, Barbara Nessim, Michael Noll, Lillian Schwartz, Roman Verostko and Mark Wilson, plus many others.

\section{The Patric Prince Collection}

The first major collection we acquired was assembled by Patric Prince, an archivist and historian of computer art who was heavily involved in SIGGRAPH, the Special Interest Group on Graphics. Patric maintained excellent contacts with many of the best known practitioners, and her collection thus includes some 200 artworks, plus a substantial amount of secondary material that helps to document the history of the genre. The Collection has a broadly international basis and is probably one of the most comprehensive in public ownership, certainly in the UK. The bulk of the artworks consist of line plotter drawings, screen prints, inkjet prints, posters and photographs, but there are also examples in other media, including 3D images and computer files. There are relatively few born-digital pieces, but most of these are currently stored on CDROMs.

Patric's husband, Bob Holzman, was head of computer graphics at the Jet Propulsion Lab in Pasadena, where he encouraged artists to make use of the organisation's mainframe computers. At the time, of course, very few institutions had the hardware, software or expertise necessary to produce computer graphics of any consequence. The collection includes a number of works by David Em, for example, who worked as artistin-residence at the Jet Propulsion Lab from 1977 to 1989. One of the earliest works he made was Aku, created in 1977 and said to be the first image of a 3D virtual world created by an artist. 
The artworks are now stored at the V\&A in South Kensington. In addition, the collection also contains a wide variety of books, archival material and ephemera, including monographs, manuals, exhibition catalogues, slides, off-prints and interviews with practising artists. These are currently stored in the Museum's Archive of Art and Design, at Blythe House, Olympia.

\section{The Computer Arts Society collection}

In addition to the Patric Prince collection, the Museum has also recently acquired the archives of the Computer Arts Society (CAS), which sought to encourage the creative use of computers in the arts. The CAS collection includes about 200 individual artworks, stored by the Society's active members until the V\&A acquired the material in 2007. Fortunately for the Museum, there is very little overlap between these two major collections, which now provide the basis for an emerging national collection of computer-generated art. Charles Csuri's Flies (1967) comes from Patric Prince, whilst his Random war (1967) comes from CAS. The Museum also holds two different versions of Ken Knowlton and Leon Harmon's Study in perception (1967). One of these is an early photographic print and the other is much more recent laser print produced in 1997. The original version was created by scanning an original photograph and then using typographic symbols to represent the greyscale values.

\section{Future collecting}

Now that the Museum is known to be collecting computer art, we are being offered additional material from various sources. Nevertheless, we still need to ensure that anything we do acquire fits with the V\&A's existing collections and future collecting plans. Generally, graphic works that have a strong design element are of real interest, whereas we would be less keen to acquire works that document the early years of (say) computer-generated music.

Museums generally understand the characteristics of works on paper and can deal with them accordingly. Nevertheless, computer-generated artworks present a number of challenges, for storage, preservation and access. For example, some older items in the collection are light-sensitive and cannot be displayed for long periods of time. In some cases the images have already faded, but are still worth preserving because of their historic significance.

Of course, we also intend to continue to acquire additional contemporary works that complement the earlier material in the collection. We have just acquired 3 recent digital prints by Mark Wilson, for example, that certainly enhance our existing holdings. At time of writing, we are also reviewing our policy for collecting born-digital works.

\section{THE PROJECT: COMPUTER ART AND TECHNOCULTURES}

When the V\&A decided to acquire the Patric Prince collection, it was clear that we would also need to obtain the resources necessary to make the collection fully accessible. From a strategic perspective, it made sense to enter into a partnership with one or more institutions with complementary interests and skills. Birkbeck had already undertaken the CACHe project, which made heavy use of the Computer Arts Society's collection. [1] It thus made sense to enter into a collaboration, rather than attempt to go it alone. The proposed project became a partnership between the School of History of 
Art, Film \& Visual Media at Birkbeck, and the Word \& Image Department at the V\&A. A bid was submitted to the Arts and Humanities Research Council's Resource Enhancement Scheme, and was ultimately successful. As a result, the project started in September 2007.

The aim of Computer Art and Technocultures is to study the development of computer-based art, principally the period from the 1970s to the 1990s. The Patric Prince collection provides the basis for the team's research, but we are also drawing on information obtained from the CAS archive and the rest of the V\&A's computer art collections. Project staff will document and evaluate the Patric Prince Collection's contents, using it to establish a framework for understanding the medium in its art historical, cultural and technological context. We also intend to link these historic developments with areas of contemporary practice in the digital arts. The project team consists of Dr Nick Lambert, Professor Jeremy Gardiner and Dr Lanfranco Aceti at Birkbeck, plus Douglas Dodds and Honor Beddard at the V\&A.

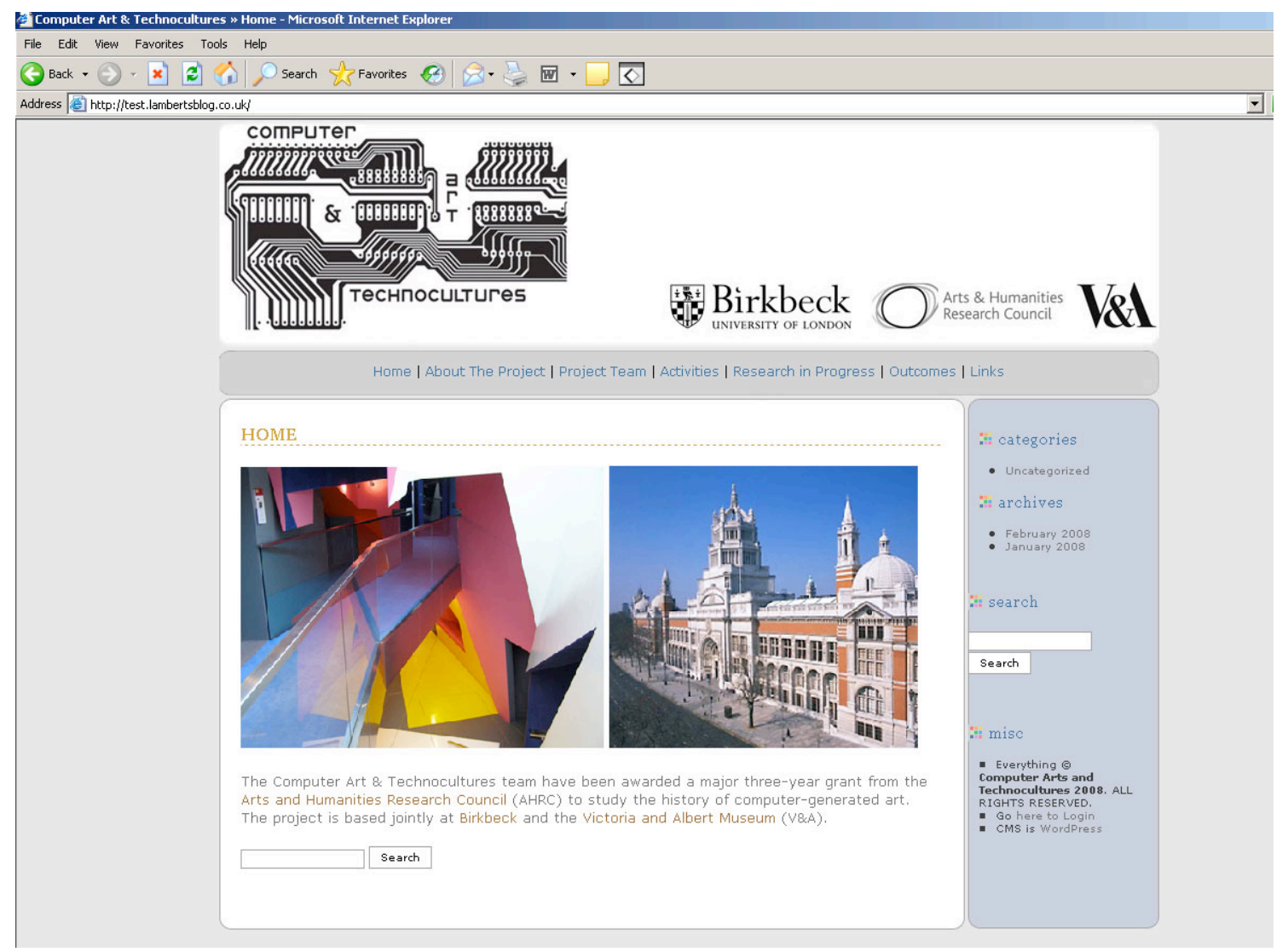

Figure 1. The project website

Documenting the collection and placing it in context

The Birkbeck team are examining the historical narrative of Computer Art, its influences from and impact upon the artistic mainstream, and its theoretical underpinnings. At the Museum, the project officer is currently cataloguing the artworks in the Patric Prince collection and comparing them with similar works from the CAS collection. In parallel, we are also digitising selected works, copyright permitting. As outlined earlier, the collection includes artworks, plus a large range of books, 
periodicals, ephemera and Patric Prince's own working records and correspondence. Inevitably, the project therefore includes an element of prioritisation. The curatorial objects are being described in the V\&A's Collections Information System (CIS), provided by System Simulation Ltd. The digital images are being created using a highspec digital camera and will be held in the Museum's digital asset management system, VADAR. This aspect of the work complements a related initiative, known as the Factory project, in which Museum staff are systematically digitising the bulk of the Department's prints, drawings, paintings and photographs. Images and descriptive text will be made available on the Museum's website via a service known as Search the Collections [2]. The books and periodicals are being catalogued using the National Art Library's Horizon computer system and the MARC21 data standard. These are already beginning to appear in the library's online catalogue [3]. The archival parts of the collection will be listed using Encoded Archival Description (EAD), an XML schema used by archivists in Britain and North America.

Thus the data that is being generated is being held in a range of systems. We plan to provide integrated access to these separate sources during the lifetime of the project, with links from the project website. The V\&A's own website will include a section dedicated to computer art, and this will bring together the various data sources. We expect that selected works from the collections will begin to appear online in the coming months.

In parallel, the researchers at Birkbeck are constructing a critical and contextual history of the genre, investigating the relationship between computer art and technocultures. The knowledge gained will be used to enhance the records created by Museum staff.

\section{Next steps}

Project staff will continue to work on documenting the collection and making it accessible to students, researchers and practitioners. We anticipate that the project will also generate one or more publications, with illustrations from the V\&A collection and elsewhere. We hope to publish this to coincide with a display of pioneering computer art at the Museum in 2010 or thereabouts, and the details of this are currently being discussed. The project team are also planning a seminar and/or conference linked to a display of contemporary digital art in 2009/10. For more information, see the project website [4].

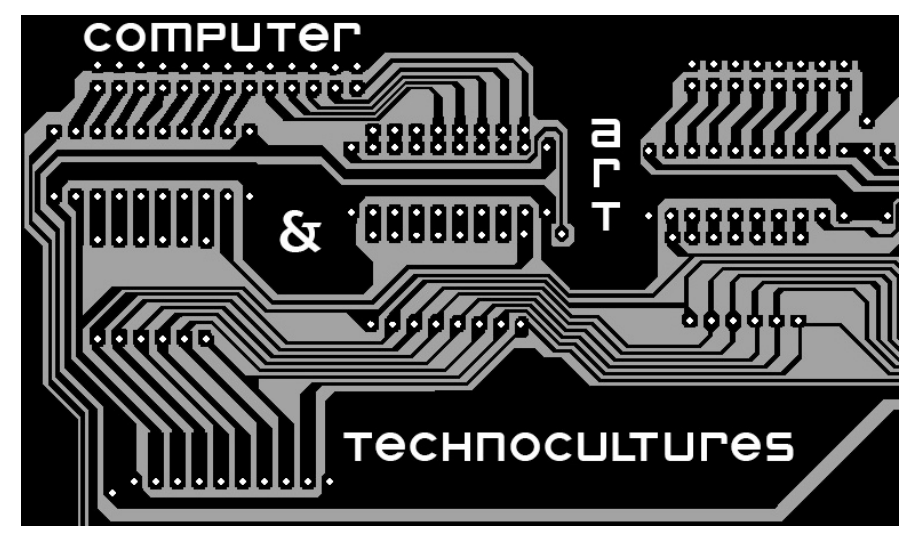




\section{ACKNOWLEDGEMENTS}

With thanks to Honor Beddard, Nick Lambert, Jeremy Gardiner and Lanfranco Aceti.

\section{References}

[1] CACHE project: http://www.e-x-p.org/cache/index.htm

[2] V\&A website: http://www.vam.ac.uk

[3] National Art Library Catalogue: http://catalogue.nal.vam.ac.uk

[4] Computer Art and Technocultures website: http://www.technocultures.org.uk 